\title{
ACETYLCHOLINESTERASE (ACHE) - POSITIVE INNERVATION OF THE GUINEA-PIG SPLEEN
}

\begin{abstract}
Katarína Schmidtová ${ }^{1}$, Mária Sirotảková ${ }^{2}$, Monika Kočišová ${ }^{1}$, Eva Mechírováa ${ }^{3}$
University P. J. Šafárik, Faculty of Medicine, Košice, Slovak Republic: Department of Anatomy ${ }^{1}$, Institute of Experimental Medicine $^{2}$, Department of Histology and Embryology ${ }^{3}$

Summary: The presence and intraorgan distribution of the acetylcholinesterase (AChE)- positive nerve structures in the guinea-pig spleen were studied by means of the direct thiocholine method. Visualized AChE-positive nerve fibres entered the guinea-pig spleen at its hilum in the vicinity of the splenic artery branches and intra parenchyma were gradually distributed to form thicker periarterial nerves and also fine adventitial nerve plexus. In described topography the AChE-positive nerve fibres were identified in association with the central artery running through the white pulp. Some of the perivascular nerve fibres associated with the central artery extended away and passed into the periarterial lymphatic sheath (PALS) to reach the marginal zone and in continuation entered into the mantle zone of lymphatic follicles. Several AChE-positive nerve fibres were seen in the red pulp but less in the splenic capsule. We did not find any AChE - positive nerve cells in the guinea-pig spleen.
\end{abstract}

Key words: Spleen; Guinea-pig; AChE; Innervation

\section{Introduction}

Primary and secondary lymphopoietic organs play important role in the immune reactions of organism and their functions are under influence of autonomous nervous system. There are several suggestions that innervation of lymphopoietic organs provides an anatomical, physiological and neurochemical basis for interactions between the nervous and immune systems $(1,6)$. The presence of autonomous nerve structures in the parenchyma of lymphopoetic organs establishes an anatomical link for translation of central neural processing into the chemical signals that can influence the immune system cells $(9,6)$. Anatomical studies discovered the presence of autonomic nerve components in perivascular localization as well as in specific compartments of primary and secondary lymphopoietic organs $(1,7,10)$.

While the species-specific differences in noradrenergic innervation of mammalian spleens are well documented $(1,3,7,14)$, little attention has been paid to study of their cholinergic innervation $(2,13)$. There is an assumption that acetylcholin (ACh) may participate in regulation of the splenic functions alone or together with other neurotransmitters.

The present study was performed to investigate the occurence, the intraorgan distribution, and morphological features of the AChE-positive nerve components in the guinea-pig spleen in postnatal period.

\section{Material and method}

The study was performed on the clinical healthy 15 adults ( 3 months old, weight $300-350 \mathrm{~g}$ ) guinea-pigs of both sexes. The directions of the Council of European Communities (86/609/EEC) on animal care have been maintained. Handling of experimental animals was performed under the supervision of the Ethical Commitee of Medical Faculty of P. J. Šafárik University. Animals were anesthetized by intraperitoneal administration of the pentobarbital ( 40 $\mathrm{mg} / \mathrm{kg}$ ) and the spleen was removed following laparotomy. The pieces of the spleen were carefully dissected and placed in the $4 \%$ paraformaldehyde ( $\mathrm{pH} 7.4$ ) at $4{ }^{\circ} \mathrm{C}$ for 4 hours. The tissue was frozen and sections of $20 \mu \mathrm{m}$ thickness were cut on a microtome. The presence of acetylcholinesterase was determined using the direct thiocholine method modified by El-Badawi and Schenk (4). Sections were incubated in acetylcholinesterase incubation medium $(\mathrm{pH}$ 5.5) for $4 \mathrm{~h}$ at $37^{\circ} \mathrm{C}$. Control sections were carried out in a medium free of iso-OMPA (as a selective inhibitor of nonacetylcholinesterases). Individual sections were mounted on slides and examined under the light microscope Nikon. 


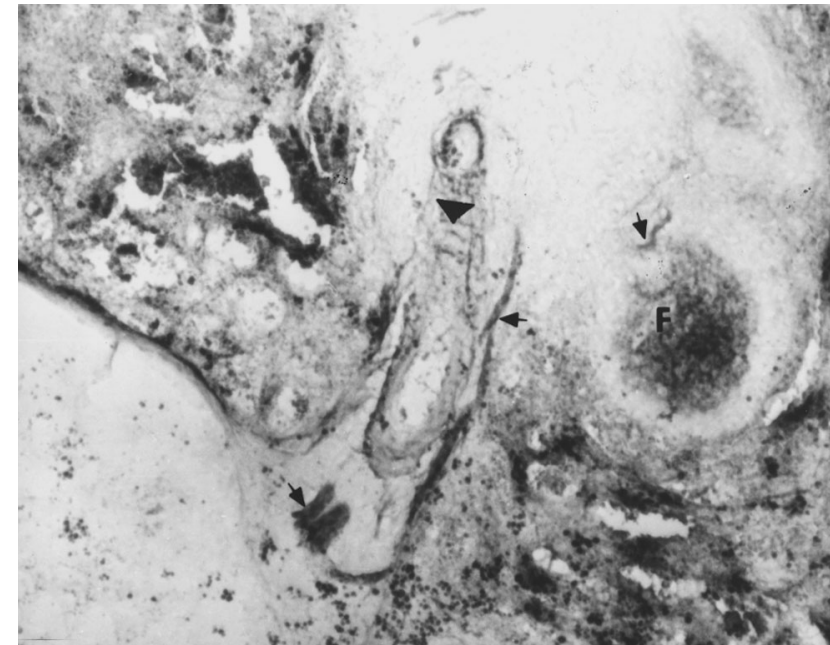

Fig. 1: Thicker periarterial AChE-positive nerves (arrows) and fine adventitial nerve plexus (arrow head) run in accompany of the splenic artery branch. Individual nerve fibres are visible in the mantle zone of lymphatic follicle (F). Magnification $125 \mathrm{x}$.

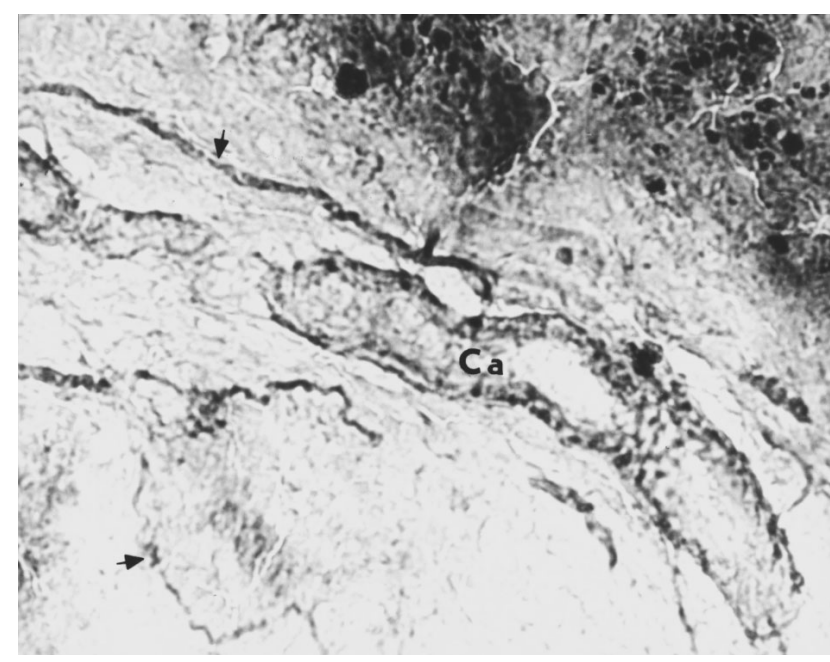

Fig. 3: The central artery $(\mathrm{Ca})$ running in the white pulp of the guinea-pig spleen. AChE-positive nerves (arrows) extend away from the periarterial course into the PALS. Some nerve fibres encircle the germinal centre of the lymphatic follicles (F). Magnification $200 \mathrm{x}$.

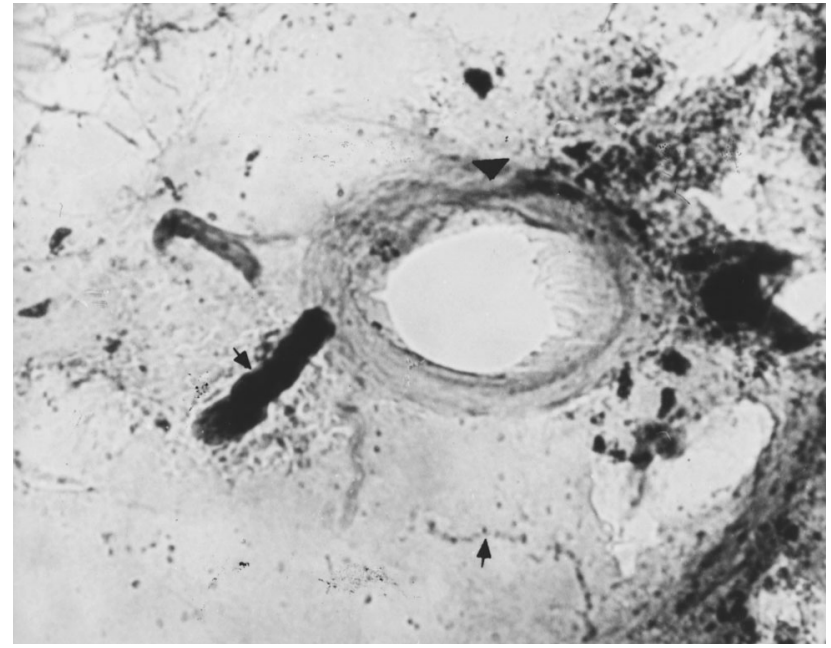

Fig. 2: Cross section through the splenic artery in the hilum with thicker periarterial AChE-positive nerves (arrows) and adventitial nerve plexus (arrow head). Fine nerve fibres extend from periarterial course and enter the parenchyma of the spleen. Magnification $200 \mathrm{x}$.

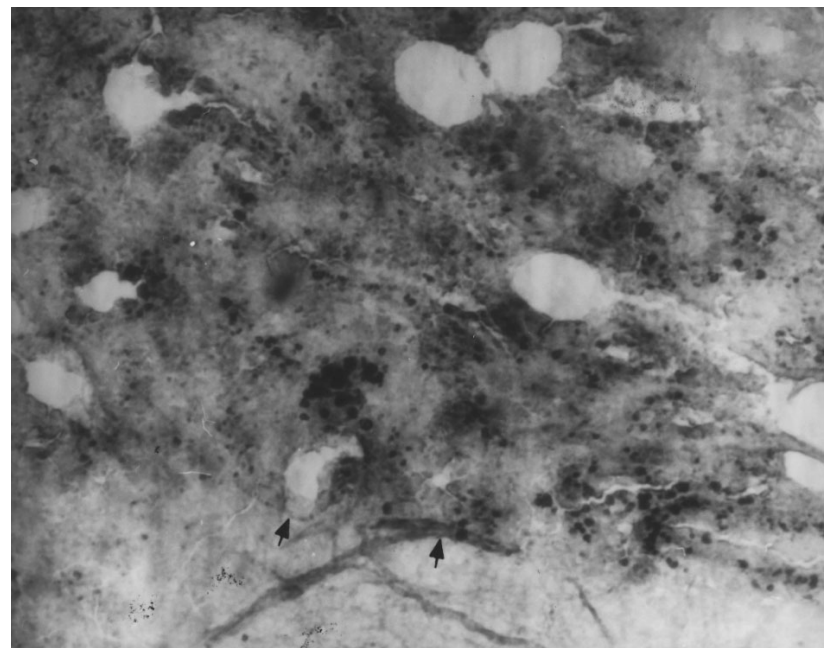

Fig. 4: AChE - positive nerve fibres (arrows) are present in the marginal zone and penetrate into the red pulp of the guinea-pig spleen. Magnification $200 \mathrm{x}$. 


\section{Results}

Visualized AChE-positive autonomous nerve fibres in a tortuous course entered into the organ at its hilum in the vicinity of the splenic artery branches. Individual varicose nerve fibres run in a common bundle with arterial branches in the form of typical carrying periarterial thicker nerves and also as more delicate nerve plexus lying in a close contact with the external side of the muscular media layer of arteries (Fig.1, 2). In both described localizations, the nerve fibres were gradually distributed inside the parenchyma of the spleen at first with trabecular arteries and further in association with the central artery running through the white pulp. Some of periarterial nerve fibres extended away from carrying perivascular nerve arrangements passing into the periarterial lymphatic sheath (PALS). In addition, delicate nerve fibres were also recorded in the mantle zone (T-lymphocytes) of lymphatic follicles encircling their germinal centers, however, as a rule, they did not penetrate into the germinal centre (Fig. 3). Whithin the PALS individual AChE-positive nerve fibres were most often seen in the marginal zone between the red and white pulp. Fine AChEpositive nerve fibres penetrate from marginal zone into the cords of the red pulp (Fig. 4) but we were less successful in proving the presence of investigated nerve fibres in the splenic capsule.

\section{Discussion}

Available literary data regarding the cholinergic innervation of the spleen are very poor in comparison with their noradrenergic and peptidergic innervation. Reilly (11) in some mammalian spleens proved the presence of the cholinergic nerve structures connected only with the splenic arterial tree. Bellinger et al. (2) and Schmidtová et al. (13) in the rat spleen observed the presence of AChE-positive nerve fibres in the white pulp around the central arteries, in the PALS, and in the marginal zone, but did not find their presence either in the lymphatic follicles or in the red pulp.

Our findings establish the existence of AChE-positive nerve fibres in the guinea-pig spleen and their intraparenchymal distribution with arterial branches. Discovered nerve fibres form very conspicuous and typical thicker nerves that fulfil the role of a carrying substrate, consisting of preterminal and terminal varicose nerve fibres. Nerve fibres lie in a close contact with the external side of the muscular media layer of vessels to form the adventitial plexus which is involved in vasomotor functions. The findings of the AChE-positive nerve fibres in the white pulp (PALS, marginal zone, and mantle zone of the lymphatic follicles) indicate their participation in neural modulation of immune functions. It is suggested that very high degree of integration exists between the immune system cells and the cholinergic innervation (12). Mentioned authors proved the fact that lymphocytes respond to the acetylcholine and are able to produce and degrade this neurotransmitter.
Althouth there appears to be an immunoregulatory relationship between splenic immune functions and the cholinergic nerve components, definitive evidence has yet to be provided.

Our findings of the AChE-positive nerve fibres in the red pulp are in contrast with described data of some authors $(2,11)$ found in the rat and rabbit spleen but are in agreement with the presence of adrenergic nerve fibres in the guinea-pig spleen (14). The occurence of the AChE-positive nerve fibres in the red pulp of the guinea-pig spleen is probably associated with the presence of contractile elements (8).

We did not find any AChE-positive nerve fibres in the guinea-pig splenic capsule but Elfvin et al. (5) and Sirotáková et al. (14) observed in this animal a dense network of immunoreactive and catecholaminergic nerve fibres in the splenic capsule, as well as, in the subcapsular compartment.

The presence of observed AChE- positive nerve fibres in several localizations of the guinea-pig spleen suggest the control of splenic functions by cholinergic nerve components. The abundant occurence of studied nerve fibres in the white pulp (PALS, marginal zone, and mantle zone of the lymphoid follicles) suggests the participation of the cholinergic nerves in immune system.

\section{Conclusions}

The findings of the AChE-positive nerve fibres in different localization of the guinea-pig spleen lead us to assume a possible effect of discovered nerve fibres not only on the vessels mentioned but also in terms of their direct effect on the immune spleen cells. The presence of these nerve fibres in the periarterial lymphatic sheath and in the mantle zone of the lymphatic follicles indicates their participation in modulation of the immune responses.

\section{Acknowledgements}

This work was supported by a VEGA grant No. 1/8294/01 Ministry of Education of Slovak Republic and by Internal grant No.19/2002/IG4 Faculty of Medicine P. J. Šafárik University, Košice.

\section{References}

1. Ackerman KD, Felten SY, Bellinger DL, Felten DL. Noradrenergic sympathetic innervation of the spleen: III. Development of innervation in the rat spleen. J Neurosci Res 1987;18:49-54

2. Bellinger DL, Lorton D, Hamili RW, Felten SY, Felten DL. Acetylcholinesterase staining and choline acetyltransferase activity in the young adult rat spleen: Lack evidence for cholinergic innervation. Brain Behav Immun 1993;7:191-204.

3. Bellinger DL, Tran L, Kang JI, Lubahn Ch, Felten DL, Lorton D. Age-related changes in noradrenergic sympathetic innervation of the rat spleen is strain dependent. Brain Behav Immun 2002;16(3):247-61.

4. El-Badawi A, Schenk EA. Histochemical methods for separate, consecutive and simultaneous demonstration of acetylcholinesterase and norepinephrine in cryostate section. J Histochem Cytochem 1967;15:580-8

5. Elfvin LG, Johansson J, Hoijer AS, Aldskogius H. The innervation of the splenic capsule in the guinea pig: An immunohistochemical and ultrastuctural study. J Anat 1994;185:276-8.

6. Felten DL. Direct innervation of lymphoid organs: Substrate for neurotransmitter signalling cells of the immune system. Neuropsychobiology 1993;28:110-2. 
7. Felten SY, Felten DL, Bellinger DL, et al. Noradrenergic sympathetic innervation of lymphoid organs. Prog Allergy 1988;43:14-36.

8. Kimura K, Fusano T, Tanaka Y. A scanning and transmission electron microscopic study of contractile trabecules in the rat spleen. Okajimas Folia Anat Jp 2001;78,(5):187-99.

9. Madden KS, Felten SY, Felten DL, Sundaresan PR, Livnat S. Sympathetic neural modulation of the immune system. Brain Behavior Immunity 1989;3:72-81.

10. Marettová E, Maretta M. The distribution of the nerve fibres in the goat lymph node. Biologia, Bratislava 2002;57(3):369-73.

11. Reilly FD. Innervation and vascular pharmacodynamics of the mammalian spleen. Experientia 1985;41:187-92.

12. Rinner I, Felsner P, Falus A et al. Cholinergic signal to and from the immune system. Immunol Lett 1995;44:217-20.

13. Schmidtová K, Bánovská E, Miklošová M. Development and distribution of acetylcholinesterase (ACHE)-positive nerve fibres in the spleen of rats and chicken. Folia Veterinaria 1995;39:75-9.

14. Sirotáková M, Kočišová M, Schmidtová K, Dorko F, Danko J. Functional morphology of adrenergic innervation of guinea pig spleen. Acta Vet Brno 2002;71:159-62.

Submitted March 2004.

Accepted June 2004.

Doc. MUDr. Katarína Schmidtová, CSc., P. J. Šafárik University,

Faculty of Medicine, Department of Anatomy, Šrobárova 2, 04180 Košice, Slovak Republic. e-mail:schmidka@central.medic.upjs.sk 